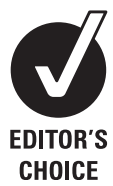

CHOICE

\title{
Developing a problem-based learning (PBL) curriculum for professionalism and scientific integrity training for biomedical graduate students
}

\author{
Nancy L Jones, ${ }^{1}$ Ann M Peiffer, ${ }^{2}$ Ann Lambros, ${ }^{3}$ Martin Guthold, ${ }^{4}$ A Daniel Johnson, ${ }^{5}$ \\ Michael Tytell, ${ }^{6}$ April E Ronca, ${ }^{7} \mathrm{~J}$ Charles Eldridge ${ }^{8}$
}

${ }^{1}$ Division Public Health Sciences, Wake Forest University Health Sciences, North Carolina \& Department of Bioethics, Trinity International University, Illinois, USA

2Department of Radiology, Wake Forest University Health Sciences, Winston-Salem, North Carolina, USA ${ }^{3}$ Center of Excellence for Research, Teaching and Learning and Department of Social Science and Health Policy, Wake Forest University Health Sciences, North Carolina, USA

${ }^{4}$ Department of Physics, Wake Forest University,

Winston-Salem, North Carolina, USA

${ }^{5}$ Department of Biology, Wake Forest University,

Winston-Salem, North Carolina, USA

${ }^{6}$ Department of Neurobiology and Anatomy, Wake Forest University Health Sciences, North Carolina, USA

${ }^{7}$ Department of Obstetrics and Gynecology, Wake Forest University Health Sciences, North Carolina, USA

${ }^{8}$ Department of Physiology and Pharmacology, Wake Forest University Health Sciences, North Carolina, USA

\section{Correspondence to}

Nancy L Jones, Strategic

Planning and Evaluation Branch (SPEB), Office of Strategic

Planning and Financial Management (OSPFM),

National Institute of Allergy and Infectious Diseases, NIH, DHHS, Building 31, 7A46F, MSC 2520, Bethesda, MD 20892, USA; jonesna@niaid.nih.gov

Received 23 December 2009 Revised 5 May 2010 Accepted 8 May 2010 Published Online First 25 August 2010

\section{ABSTRACT}

A multidisciplinary faculty committee designed a curriculum to shape biomedical graduate students into researchers with a high commitment to professionalism and social responsibility and to provide students with tools to navigate complex, rapidly evolving academic and societal environments with a strong ethical commitment. The curriculum used problem-based learning (PBL), because it is active and learner-centred and focuses on skill and process development. Two courses were developed: Scientific Professionalism: Scientific Integrity addressed discipline-specific and broad professional norms and obligations for the ethical practice of science and responsible conduct of research (RCR). Scientific Professionalism: Bioethics and Social Responsibility focused on current ethical and bioethical issues within the scientific profession, and implications of research for society. Each small-group session examined case scenarios that included: (1) learning objectives for professional norms and obligations; (2) key ethical issues and philosophies within each topic area; (3) one or more of the RCR instructional areas; and (4) at least one type of moral reflection. Cases emphasised professional standards, obligations and underlying philosophies for the ethical practice of science, competing interests of stakeholders and oversight of science (internal and external). To our knowledge, this is the first use of a longitudinal, multi-semester PBL course to teach scientific integrity and professionalism. Both faculty and students endorsed the active learning approach for these topics, in contrast to a compliance-based approach that emphasises learning rules and regulations.

While the scientific community generally endorses the importance of scientific integrity, in practice it relies heavily on mentoring to informally transmit values affecting the ethical conduct of research. After two decades of requiring training in responsible conduct of research (RCR) by the National Institutes of Health (NIH) ${ }^{1}{ }^{2}$ and more recently by the National Science Foundation, ${ }^{3}$ certain common desired knowledge, skills, attitudes and behaviours have emerged. ${ }^{245}$ Goals for instruction in scientific integrity include decreasing research misconduct and promoting standards of scientific conduct. ${ }^{4} 6$

Wake Forest University promotes professionalism and social responsibility for research and strives to equip our students with the skills to navigate the research environment with scientific integrity. We designed a curriculum that uses problem-based learning (PBL) embedding several educational principles effective for adult learning and recommended for promoting scientific integrity. $^{2} 7$ These include a sequenced approach across graduate school training, ${ }^{8}$ an active rather than passive learner-centred approach and case scenarios with problems relevant to the learner's needs. ${ }^{10-12}$

The small-group design, with faculty facilitators, encourages open communication and socialisation around professional norms. Scientists with high status, resources and symbolic value affect the degree to which members of organisations internalise norms. ${ }^{9} 1314$ Small groups create a close proximity to role models (facilitators) to affect behaviour in a positive way by leveraging identity as part of the culture and internalisation of norms. ${ }^{15} 16$ The course embedded moral reflection into the cases to facilitate peer discussion and concentrated practice in moral problem-solving, to take advantage of the positive relationship between moral reasoning and moral behaviour. ${ }^{17}$

PBL uses cases that comprise authentic 'realworld' dilemmas and require students to acquire new knowledge to resolve the problem. Unlike case-based learning, which presents new content and then demonstrates its application with a case study using the new information, PBL is student centred; the quest for more information drives student learning in a collaborative, group-centred, hands-on setting. ${ }^{18}$ Two fundamental pedagogical principles underlie PBL: students learn best (1) in groups rather than alone and (2) when they actively participate in identifying and addressing their knowledge gaps.

PBL differs from other case-based instructional methods in several ways. It encompasses the ' $5 \mathrm{E}$ ' instructional model (engage, explain, explore, elaborate and evaluate), and each problem-case unfolds over two group sessions separated by 4 to 7 days, to promote a learning cycle. In session one, students identify learning issues needed to solve the problem. During the interval, individual students acquire specific content knowledge to address these learning issues. At the second session, students collaboratively use their knowledge and resources to solve more complex controversies and problems revealed as the case continues.

Although most US medical schools make some use of the PBL approach for developing skills, shaping attitudes and transmitting didactic knowledge $^{19}$ and some PBL cases for research ethics have been developed, ${ }^{20}$ we are unaware of another longitudinal multi-semester $\mathrm{PBL}$ curriculum to teach scientific integrity to biomedical graduate students. Thus, the purpose of this report is to 
document this institutional experience in designing and implementing an innovative new curriculum that also incorporates the NIH basic principles for RCR instruction. ${ }^{2}$

\section{METHODS}

Wake Forest University School of Medicine (WFUSM) implemented PBL as a principal educational strategy for medical students in 1987. This provided rich resources for developing course materials, including a grading rubric and facilitator training materials. Earlier RCR and bioethics graduate courses at Wake Forest University, as well as the nine RCR instructional areas on the Office of Research Integrity (ORI) website (ie, data acquisition, management, sharing and ownership, conflict of interest and commitment, human subjects, animal welfare, research misconduct, authorship, mentor/trainee responsibilities, peer review and collaborative science) provided examples for cases and objectives.

After discussions with the graduate school dean and graduate programme directors, the graduate programmes recommended a curriculum design to fit within the first 2 years of graduate student training. These mandatory courses for all biomedical graduate programmes $(11 \mathrm{PhD}$ programmes and $1 \mathrm{MS}$ programme) fulfilled the graduate school's training requirements for RCR.

We created an Advisory Committee for Ethics and Professionalism, composed of faculty, postdoctoral fellows and graduate students from 14 departments at the two campuses of Wake Forest University and the joint biomedical engineering programme with the Virginia Polytechnic Institute and State University in Blacksburg, Virginia. The Advisory Committee prioritised case topics based on relevance to their graduate students' needs and advised on the implementation of the course, such as synchronising topics to student experiences. Our prototype cases were tested with faciliators and graduate students and the feedback was used to refine the cases and develop faciliator case notes. The faciliator case notes helped to ensure consistently effective quality of delivery for different groups.

The WFUSM Department of Academic Computing provided electronic delivery of course materials through an established enterprise-level web-based courseware system that 'releases' the PBL cases to students at the start of the small group's scheduled meeting times. This system promoted 'real-time' analysis and discussion of events.

\section{RESULTS}

Curriculum materials included 14 cases (see table 1), corresponding facilitator case notes, course administration materials, a grading schema, evaluation forms and facilitator training materials.

Course faculty introduced the course objectives, the PBL method, RCR concepts and pilot cases to first-year graduate students during their orientation period.

All WFUSM graduate students must take four one-credit courses: Scientific Professionalism: Scientific Integrity (I and II) during the first year, and Scientific Professionalism: Bioethics and Social Responsibility (III and IV) during the second year (table 1). First-year cases focus on the discipline-specific and broad professional norms and obligations for the ethical practice of science and the principles of responsible conduct of research. Topics include the student-advisor relationship, laboratory personnel dynamics, research collaborations, appropriate handling of data, attribution of credit, plagiarism, rights of conscience and ethical issues in animal and human research. Second-year cases focus on current ethical and bioethical issues within the scientific profession and the implications of research for society. Topics include entrance of bias into research, limits of scientific authority, conflicts of interest, peer review, dual-use research and commercialisation and globalisation of science. Each case presents realistic, professional conflicts and ethical dilemmas that range from very subtle to overt misconduct. Each course builds on prior ones, increasing the complexity and sensitivity of issues while taking advantage of increased competency with the PBL method and enhanced group functioning.

\section{Small-group design}

Graduate students work in small groups of 6-8, with two facilitators serving as metacognitive coaches and process facilitators. Each group includes students from diverse graduate programmes and nationalities. The metacognitive facilitator ensures that students acquire PBL skills and process for appropriate group dynamics. The initial implemenation relied heavily on graduate faculty who were experienced medical school PBL facilitators. By the second year of implementation, postdoctoral fellows were trained as facilitators using a newly developed certification programme that included sections on how to facilitate PBL courses, principles and values in science, RCR and moral reflection. Postdoctoral fellows were paired with a faculty facilitator.

\section{Facilitator training}

Trained and experienced facilitators, serving as cognitive coaches rather than content experts, are key to ensuring that case delivery conforms to the designed methodology and achieves case objectives. We created a training document, A Guide to Facilitating the Scientific Professionalism Courses, that describes course philosophy and structure, $\mathrm{PBL}$ methodology, moral reasoning techniques, the small-group facilitation process and facilitator role obligations (eg, debriefing, providing feedback, grading, etc). We also developed a detailed rubric to promote uniform evaluation across groups (see Grading section below and table 2).

The PBL method takes advantage of a dynamic that emerges from the group's members as they interact with issues or conflicts being discussed. The best way to learn to process and facilitate this dynamic is to practise with each other by assuming roles as facilitators and students. The novices then receive suggestions on how to improve their performance, and an explanation of how the group's observations relate to the evaluation rubric.

\section{Structure of the curriculum cases}

Each case emphasises certain professionalism issues in the biomedical research culture, with students given specific professional roles (eg, first-year student, advanced student, postdoctoral fellow, principal investigator). Giving each group member a specific role in each case drives moral reasoning more strongly than typical case discussion, which drives abstract problem-solving. Each case brings out learning objectives covering professional norms and obligations as well as key ethical issues for the topic area, one or more of the RCR instructional areas, principles of scientific practice and virtues of scientists (table 1). We designed scenarios to foster a realistic understanding of the practice and social nature of science. The cases go beyond a simple coverage of RCR and overt research misconduct by addressing the need to manage competing interests of various stakeholders and to deal constructively with 
Table 1 Overview of PBL Ethics and Professionalism curriculum

\begin{tabular}{|c|c|c|c|c|}
\hline Course & Case title and content & RCR element & Principles* & Virtues* \\
\hline \multirow[t]{2}{*}{$\begin{array}{l}\text { Orientation: Introduction } \\
\text { to PBL }\end{array}$} & $\begin{array}{l}\text { Picking a Laboratory } \\
\text { Practice of science and } \\
\text { mentor-trainee relationship }\end{array}$ & Mentorship & Community of science & Excellence, respect \\
\hline & $\begin{array}{l}\text { Being a Scientist } \\
\text { Practice of science and } \\
\text { scientific norms }\end{array}$ & NA & $\begin{array}{l}\text { Objectivity, research } \\
\text { reproducibility }\end{array}$ & Duty, altruism \\
\hline \multirow[t]{4}{*}{$\begin{array}{l}\text { Course 1: Scientific } \\
\text { Professionalism: Scientific Integrity }\end{array}$} & $\begin{array}{l}\text { Mentors and Money } \\
\text { Financial awareness }\end{array}$ & Mentorship & Community of science & Excellence, respect \\
\hline & $\begin{array}{l}\text { Reviewing the Literature } \\
\text { Plagiarism }\end{array}$ & $\begin{array}{l}\text { Research misconduct, } \\
\text { authorship }\end{array}$ & Community of science & $\begin{array}{l}\text { Excellence, accountability, } \\
\text { respect }\end{array}$ \\
\hline & $\begin{array}{l}\text { Team Work } \\
\text { Lab etiquette, group } \\
\text { collaboration }\end{array}$ & Collaboration & $\begin{array}{l}\text { Research freedom, community } \\
\text { of science }\end{array}$ & $\begin{array}{l}\text { Excellence, accountability, } \\
\text { respect }\end{array}$ \\
\hline & $\begin{array}{l}\text { Whose Turn Is It? } \\
\text { Publications and attributing } \\
\text { credit }\end{array}$ & Authorship & $\begin{array}{l}\text { Community of science, research } \\
\text { reproducibility }\end{array}$ & Respect \\
\hline \multirow[t]{4}{*}{$\begin{array}{l}\text { Course 2: Scientific } \\
\text { Professionalism: Scientific Integrity }\end{array}$} & $\begin{array}{l}\text { Phantom Bands } \\
\text { Standards for reporting results }\end{array}$ & $\begin{array}{l}\text { Data management and } \\
\text { conflicts of interest }\end{array}$ & Research reproducibility & $\begin{array}{l}\text { Respect, accountability, } \\
\text { altruism }\end{array}$ \\
\hline & $\begin{array}{l}\text { Conscientious Objectors } \\
\text { Values and biases in science }\end{array}$ & NA & $\begin{array}{l}\text { Questioning certitude, objectivity, } \\
\text { research freedom }\end{array}$ & Respect \\
\hline & $\begin{array}{l}\text { People, Places and Things } \\
\text { Translational research and } \\
\text { human subject research }\end{array}$ & $\begin{array}{l}\text { Human Subjects, Conflicts of } \\
\text { Interest }\end{array}$ & $\begin{array}{l}\text { Respect for subjects, community } \\
\text { of science, objectivity }\end{array}$ & Duty, altruism \\
\hline & $\begin{array}{l}\text { A Fine Mess } \\
\text { Research oversight and animal } \\
\text { research }\end{array}$ & Animal subjects, mentorship & Respect for subjects & Duty, altruism, excellence \\
\hline \multirow[t]{2}{*}{$\begin{array}{l}\text { Course 3: Scientific } \\
\text { Professionalism: Bioethics } \\
\text { and Social Responsibility }\end{array}$} & $\begin{array}{l}\text { It Cuts Both Ways } \\
\text { Dual use and obligations to } \\
\text { oversee and peer review } \\
\text { research }\end{array}$ & $\begin{array}{l}\text { Research misconduct, } \\
\text { authorship, peer review, } \\
\text { collaboration, conflicts } \\
\text { of interest }\end{array}$ & $\begin{array}{l}\text { Community of science, research } \\
\text { reproducibility }\end{array}$ & Duty, accountability \\
\hline & $\begin{array}{l}\text { Confidentiality And Collegiality } \\
\text { Peer review }\end{array}$ & $\begin{array}{l}\text { Peer review, conflicts } \\
\text { of interest }\end{array}$ & $\begin{array}{l}\text { Community of science, research } \\
\text { reproducibility }\end{array}$ & Accountability, altruism \\
\hline \multirow[t]{2}{*}{$\begin{array}{l}\text { Course 4: Scientific } \\
\text { Professionalism: Bioethics } \\
\text { and Social Responsibility }\end{array}$} & $\begin{array}{l}\text { Patent Pending } \\
\text { Commercial influences in } \\
\text { academic research }\end{array}$ & Conflicts of interest & $\begin{array}{l}\text { Research reproducibility, } \\
\text { objectivity }\end{array}$ & Altruism, integrity \\
\hline & $\begin{array}{l}\text { 'And the Band Played On' } \\
\text { Capstone Experience (movie) }\end{array}$ & $\begin{array}{l}\text { Research misconduct, } \\
\text { collaboration, conflicts } \\
\text { of interest }\end{array}$ & $\begin{array}{l}\text { Objectivity, collaboration, } \\
\text { research reproducibility }\end{array}$ & $\begin{array}{l}\text { Duty, integrity, accountability, } \\
\text { altruism }\end{array}$ \\
\hline
\end{tabular}

${ }^{*}$ Adapted from Jones ${ }^{28}$

NA, not applicable; PBL, problem-based learning.

difficult conversations and questionable research practices. Some cases also touch on current philosophical, ethical and bioethical issues within the scientific profession, and implications of research for society. The curriculum design promotes selfdirected learning by requiring each student to prepare a written assignment during the intersession of each case.

A major goal of the curriculum is to develop ethical reflection skills by embedding into each case questions that address one or two of the following concepts: moral sensitivity, moral

Table 2 Example of a student evaluation rubric (individual skills in group process)

\begin{tabular}{ll}
\hline Grade & Examples to identify \\
\hline 4 (A) & $\begin{array}{l}\text { Leader in setting and maintaining agenda; very sensitive to peers; promotes } \\
\text { involvement of other group members; provides constructive correction }\end{array}$ \\
3 (B) & $\begin{array}{l}\text { Conscious of time and agenda; shares information; is accepted and trusted } \\
\text { by group members; displays adequate skill in expressing knowledge and } \\
\text { opinions }\end{array}$ \\
2 (C) & Significant difficulty in expressing self; shares inappropriate information not
\end{tabular}

2 (C) Significant difficulty in expressing self; shares inappropriate information not germane to conversation; not interested in group process; shows effort at improvement; retains low leadership qualities

1 (F) Chronically late or absent; disrupting and/or dominating to point of group irritation; excessively shy and unwilling to contribute; uninterested in cooperation or group progress.

Each student evaluation criterion has a rubric with descriptive phrases that exemplify behaviours considered superior ( 4 or $A)$, competent ( 3 or $B$ ), needs improvement ( 2 or $C$ ), or unacceptable (1 or F), to guide facilitators in arriving at objective, uniform evaluations. reasoning and judgement, moral motivation and commitment, and moral character and competence. ${ }^{21} 22$ The curriculum promotes moral sensitivity, the ability to see things from the perspective of others and to be aware of legal, institutional and national concerns, by presenting situations in which the ethical issues are not predigested or interpreted. This technique promotes student awareness of nuances as they learn to distinguish relevant from irrelevant information and encounter pertinent research customs, rules, regulations and laws. The curriculum frequently requires students to consider the case from various stakeholders' points of view to promote the development of sensitivity to ethical issues likely to arise in the research setting.

The curriculum promotes moral motivation and commitment, developing a sense of professional identity and internalisation of the scientific culture's norms and values, by structuring some cases that require students to consider their choices and decisions as a professional scientist. Also, some characters in the cases are exemplar scientists.

Moral character and competence focuses on skills such as interpersonal interactions and problem-solving. Small-group design promotes interpersonal interactions and improves the participants' group skills. Most scenarios require students to defend their choices and decisions by supplying criteria for their judgements. Some scenarios become very active by requiring role-playing. 
Moral reasoning and judgement is learning how to weigh the principles, values and consequences embedded in moral judgements. Forcing choices and decisions elicits better moral reasoning and judgement rather than relying on abstract problem-solving. For this activity, we drew on two published moral reasoning methods: Developing a Well-Reasoned Response to a Moral Problem in Scientific Research Ethics ${ }^{23}$ and Three Quick Ethics Questions ${ }^{24}$ (table 3).

\section{Debriefing group activity}

Each case concludes with a debriefing activity designed to (1) reinforce the course expectations, (2) reveal the concrete learning objectives and skills acquired during the case and (3) improve the group's functioning through feedback. Debriefing assures students who are more accustomed to didactic instruction that they are still acquiring important content and skills. Moreover, if not brought up in prior discussions, debriefing links the importance and relevance of each case's content to current headlines and discussions in the present-day scientific, regulatory and political arenas.

\section{Facilitator case notes}

A major advantage of the PBL format is that facilitators do not need to be content experts; their role is to promote effective student discussion of case issues. However, it became necessary to develop extensive case notes to present facilitators an overview of the specific skills, learning issues, content resources and discussion guide. Notes (which students do not receive) include a brief case synopsis, listings of case objectives, RCR elements, values, principles and type(s) of moral reflection embedded in each case. Table 4 shows a truncated example; complete facilitator notes typically encompass 10 or more pages of discussion.

\section{Evaluation}

The grading philosophy of the faculty reflected the curricular goals of helping students recognise important ethical issues in the practice of science and developing their skills at moral reasoning, effective group participation, self-directed learning, and articulation, defence and critique of reasoned arguments. Each student was graded pass or fail on the following four criteria: (1) problem analysis, moral reflection and reasoning, (2) self-directed learning, knowledge acquisition and written assignments, (3) individual skills in group process and (4) group

Table 3 Examples of two moral reasoning methods used in case discussions

\begin{tabular}{|c|c|}
\hline \multicolumn{2}{|l|}{ A. Three Quick Ethics Questions* } \\
\hline Test & Purpose \\
\hline $\begin{array}{l}\text { Impartiality: Would you agree to } \\
\text { this action if you were in the other } \\
\text { person's place? }\end{array}$ & $\begin{array}{l}\text { Corrects for self-interest: invokes the } \\
\text { golden rule: 'Do unto others as you would } \\
\text { have them do unto you.' }\end{array}$ \\
\hline $\begin{array}{l}\text { Universalisability: Would you be } \\
\text { comfortable if everyone acted as } \\
\text { you propose to do, in this circumstance? }\end{array}$ & $\begin{array}{l}\text { Adjusts for applicability: Invokes Kant's } \\
\text { categorical imperative-that is, if a rule is } \\
\text { difficult to maintain, investigate why. }\end{array}$ \\
\hline $\begin{array}{l}\text { Justifiability: Can I explain openly to } \\
\text { the public, my superiors or peers my } \\
\text { reasons for acting as I propose }\end{array}$ & $\begin{array}{l}\text { Validates one's reasoning: How can you } \\
\text { defend your reasoning if you're not willing } \\
\text { to support it openly? }\end{array}$ \\
\hline
\end{tabular}

B. Developing a Well-Reasoned Response to a Moral Dilemma†

1. What are the issues or points in conflict?

2. Who are the stakeholders?

3. What is each stakeholder's obligation, duty or responsibility?

4. List the possible actions and consequences to each stakeholder.

${ }^{*}$ Adapted from Iserson. ${ }^{24}$

†Adapted from Bebeau et al ${ }^{23}$ (http://poynter.indiana.edu/mr/mr-main.shtml). process development (effectiveness of the whole group) (see sample rubric in table 2).

\section{CONCLUSION}

Kalichman proposed three goals for RCR education: 'empowering trainees to respond to the ethical challenges raised in the conduct of research, increasing awareness of the purpose and value of ethical decision making as well as the roles and responsibilities of whistleblowers, and fostering a positive attitude about promoting an environment that values RCR'. ${ }^{25}$ Often, scientists equate integrity with preventing research misconduct-for example, falsification, fabrication and plagiarism. The research community is skeptical of a complianceoriented approach to training in scientific integrity, because it is often seen as a thinly-veiled harangue on what is wrong with the practice of science. Merely teaching rules and regulations will not ensure ethical behaviour. Alternatively, excessive focus on survival skills can have an unintended consequence of endorsing questionable research practices in the name of career success and self-preservation. ${ }^{26}$ In response, newer prototypes for scientific integrity training use a broader approach by incorporating both micro-ethics (for example, making ethical choices in the practice of research) and macro-ethics (for example, ethical issues in larger social and institutional settings). ${ }^{27}$ Our curriculum embraces this more expansive coverage of scientific integrity that focuses on learning the role obligations of scientists, micro- and macro-ethics and acquiring skills.

The deliberately complex problems in our cases are well suited to provide contextually relevant ethical and professional problems in the practice of research, as well as broader contemporary bioethical issues in scientific research. The PBL design permits utilisation of different approaches to unravel the components of a problem, such as the four types of moral reflection. The curriculum also fosters development of various skills, such as the scientific process (eg, resource evaluation, data collection, analysis and interpretation); recognition of ethical issues in the practice of science; sound moral reasoning, effective group and team work (clear communication, facilitating discussion, constructive critique); self-directed learning skills and application of new knowledge; and articulating, defending and critiquing one's professional decisions with reasoned arguments.

We propose that students do not need explicit education in ethical theory. However, students found the two moral reasoning techniques taught in the curriculum (table 3) useful, because they afford a concrete method for working with abstract ethical concepts. A larger issue was confronting the myth that it is impossible to teach ethics. There is no doubt that the moral underpinnings learned early in life highly influence one's future ethical conduct. However, it is equally important to recognise that '... the correct conduct of science cannot have been learned in childhood since many scientific practices (eg, authorship practices, the confidentiality of peer review) are not elements of childhood' ${ }^{28}$ More to the point, graduate students in science should begin to consider themselves members of the scientific community who are becoming independent professionals. To do so, they need explicit training in the expectations and norms for practising science. Initial student feedback on our curriculum also indicated that some students believe that ethics are personal and were uncertain whether their personal decisions should be discussed openly. We contend that members of the scientific community should be able to justify their actions to peers and to society on the basis of professional norms.

At first, some students resisted the PBL method because of unfamiliarity and a preference for pre-identified learning 
Table 4 Example overview of a facilitator's case notes

\begin{tabular}{|c|c|}
\hline Case title: & Confidentiality and collegiality, peer review \\
\hline & $\begin{array}{l}\text { RCR: peer review, conflict of interests } \\
\text { Principle of practice: community of science, research reproducibility } \\
\text { Virtue: accountability and altruism }\end{array}$ \\
\hline Learning objectives & $\begin{array}{l}\text { 1. Explain the roles of an author, reviewer and editor in the peer review of a manuscript. } \\
\text { 2. Discuss how scientists, as members of the community of science, have an obligation to serve as reviewers of research in order } \\
\text { to move knowledge forward and to ensure the veracity of results and technology. } \\
\text { 3. Compare and contrast peer review of journal articles with research grant applications. } \\
\text { 4. Deduce some obligations of reviewers (eg, confidentiality, objectivity, fairness of review and reviewing within their scope of expertise). } \\
\text { 5. Examine how conflict of interest is a major ethical issue for peer review-for example, institutional affiliation, relationships with colleagues } \\
\text { (past or present), scientific bias (including opposing theories), financial impact of data. } \\
\text { 6. Discover ethical issues in peer review-for example, using results prior to open publication, unfair critique, reviewing without an } \\
\text { editor's approval, reviewing without appropriate expertise, difficulty remaining objective, giving insider information on a grant or paper outcome. } \\
\text { 7. Synthesise the elements of a good review-for example, being timely, critiquing the experimental design, assessing the strengths/limitations, } \\
\text { judging the appropriateness of the analysis, accurate interpretation of the findings, conclusions, significance, and quality of references. } \\
\text { 8. Recommend ways to deal with controversies or conflicts that might arise in the process of authorship or peer review. }\end{array}$ \\
\hline
\end{tabular}

Synopsis Students are placed in the scenario as a finishing graduate student in the lab of a frequent journal reviewer. PI asks student to review three manuscripts that the PI is unable to complete in a timely manner. Two are not challenging because the student is familiar with the labs and their work; the third paper is outside the student's expertise, so he asks a postdoc expert for help. The case is used to expose policies, limitations and roles for appropriate manuscript review. Session 2 builds on principles of peer review by placing the students as a senior postdoctoral fellow in a lab invited to be an ad hoc reviewer for a study section. Short vignettes describe some tensions of peer review. Proposal 1: The reviewer knows the applicant and has negative results of their own that show the applicant's experiments are conceptually flawed. Proposal 2: Gives the reviewer a great idea to begin new experiments of his own. Proposal 3: The applicant references preliminary data using a reagent the reviewer's lab developed but the reviewer is unsure how the applicant could have got ten those reagents. Proposal 4: A less than meritorious application from a minority applicant. Proposal 5: Poses whether to reveal insight into the review results to the applicant, a close colleague.

Moral reflection $\quad$ Moral motivation and commitment Students are asked to identify best practices of peer review and those actions that are outside the ethical bounds of the profession of scientists.

\author{
Assignment Students develop the following: \\ - A list of activities for which the scientific community practices peer review-that is, journals, grant proposals, promotion, committees. \\ Describe the typical practices and the key roles in these activities (eg, editor, reviewer). \\ - A list of essential key elements of a good peer review. \\ - A list of the greatest ethical risks in a peer review, and how to mitigate those risks. \\ - An example within their discipline of an ethical issue within peer review.
}

$\mathrm{Pl}$, principal investigator; RCR, responsible conduct of research.

objectives within a didactic format. By the second semester, however, students became competent and more comfortable with the format. Because group facilitators are not content experts who provide 'correct' solutions for cases, ultimate responsibility for learning rests on the students, both individually and as a group. The process requires them to become selfdirected, independent learners by exploring various hypotheses and approaches to address the central problem(s) of each case. On the other hand, negative comments from students about facilitators who attempted to dominate discussion with monologues about their own experiences endorsed the value of the PBL methodology. Students want, and will accept responsibility for, their own learning and will take the initiative to keep their group discussions aligned with PBL principles.

Our curriculum design also facilitates students' ability to develop an identity as a professional, socialise around professional norms, acculturate to a strongly embedded ethos and acquire moral reflection skills such as moral reasoning. The small-group design is important for helping individuals internalise norms and values-for example, having open communication and socialisation to cultural norms with peers and role models. ${ }^{15} 16$ If one goal is to affect ethical behaviour, then shaping the organisational ethical code of conduct is essential. ${ }^{29}$ Another advantage of the small-group design is that the graduate faculty serve dual functions, as metacognitive group coaches and as role models. This format counters a tendency for graduate students to become isolated too quickly within narrow laboratory social structures and it expands their network of peers, role models and mentors in ways that persist after the completion of the course. Further, through our evaluation scheme, we emphasise the importance of skill development to promote lifelong learning.

The importance of institutional support for a PBL curriculum cannot be overstated. The small-group format with two facilitators is labour-intensive and requires significant logistical support to coordinate multiple groups and schedules. However, our institution reconciled this investment through its commitment to create a community that values scientific integrity. The graduate school leadership also recognised that the curriculum fulfilled larger training needs in two important ways: (1) the PBL format provides concentrated practice working in groups, thereby developing students' interpersonal skills and their ability to articulate, defend and critique professional decisions; and (2) the PBL format increases the faculty's competency in ethics, because they also learn while facilitating discussions. In addition, the curriculum provides junior faculty and postdoctoral trainees an opportunity to build a teaching portfolio and fulfil newer requirements for RCR training, ${ }^{2}$ while still meeting other professional demands within a research-intensive institution.

Essential factors for the successful development and implementation of our curriculum included, first and foremost, support from the graduate school deans, who decided to mandate the programme for all graduate students and used it to fulfil the institutional RCR training requirements. Our earlier extensive experiences with $\mathrm{PBL}$ for medical education, and earlier RCR and bioethics courses, enabled quicker curriculum development. Receiving cross-graduate programme input through the Advisory Committee for Ethics and Professionalism and conducting a formal evaluation of the curriculum (the 
subject of a companion paper) were also important. These stages actively involved graduate students, postdoctoral fellows and faculty in refining the curriculum-and in the process they became avid supporters of the endeavour.

Kalichman and Plemmons asserted that '[t]he implicit question is, therefore, if responsible conduct is essential to being good scientists, then how are the relevant knowledge, skills and attitudes, and behaviors to be taught, and by whom?' We propose that the relevant knowledge should include a realistic understanding of the practice of science. Skills should include the ability to recognise ethical issues in the practice of science, to understand the ethical implications of science for society, to reason ethically, to work effectively within groups and to articulate and defend one's professional judgement. Students should acquire attitudes regarding acculturation to the norms of professional science, principles and values of science and its obligations and virtues. All faculty, especially research advisors, should be instructors for transmission of these important skills and values for the scientific community. A curriculum such as this will prepare graduate students to be future leaders in our rapidly changing professional environment.

Acknowledgements In addition to the authors, members of the Advisory Committee for Ethics and Professionalism were: Virginia Polytechnic Institute and State University faculty H Clay Gabler. Wake Forest University faculty Drs Bernard A Brown, David Roberts, Craig Hamilton and David Lyons; postdoctoral fellow Dr Ellen Palmer; and graduate students Jason Graves, Meghna B Ostasiewski, Jennifer Mozolic and Heather Cohn. Dr Muriel Bebeau served as a consultant during the early conceptualisation of the curriculum. The authors thank Drs Gordon Melson and Lorna Moore, graduate deans of Wake Forest, who provided essential support for this project. The authors also owe a sincere indebtedness to Susan Pierce, graduate school registrar, who provided invaluable insights during design and implementation and played the major role in ensuring logistical support.

Funding This project was supported by NSF 0530023 from the National Science Foundation (JCE, principal investigator)

Competing interests None.

Provenance and peer review Not commissioned; externally peer reviewed.

\section{REFERENCES}

1. NIH. Requirement for Programs on the Responsible Conduct of Research in National Research Service Award Institutional Training Programs NIH Guide for Grants and Contracts. Volume 18. 1989;1.

2. NIH. Update on the Requirement for Instruction in the Responsible Conduct of Research NOT-OD-10-019 ed: NIH Guide for Grants and Contracts, 2009.

3. Responsible Conduct of Research NSF's Implementation of Section 7009 of the America COMPETES Act. Federal Register. Volume 74: Federal Register, 2009:42126-8.
4. Kalichman MW, Plemmons DK. Reported goals for responsible conduct of research courses. Acad Med 2007;82:846-52.

5. Health Nlo. Update on the Requirement for Instruction in the Responsible Conduct of Research. http://grants.nih.gov/grants/guide/notice-files/NOT-OD-10-019.html, 2009.

6. Steneck NH, Bulger RE. The history, purpose, and future of instruction in the responsible conduct of research. Acad Med 2007:82:829-34.

7. IOM. Integrity in Scientific Research: Creating an environment that promotes responsible conduct. Washington, DC: The National Academies Press, 2002

8. Davis $\mathbf{D}, 0$ 'Brien MA, Freemantle $\mathrm{N}$, et al. Impact of formal continuing medical education: do conferences, workshops, rounds, and other traditional continuing education activities change physician behavior or health care outcomes? JAMA 1999;282:867-74.

9. OGE. Executive Branch Employee Ethics: Survey. Washington, DC: US Office of Government Ethics, 2000.

10. Knowles M. The modern practice of adult education: Andragagy versus pedagogy New York, NY: New York Association Press, 1970

11. Cross K. Adults are Learners: Increasing participation and facilitating learning. San Franscisco, CA: Jossey-Bass, 1981

12. Brookfield S. Understanding and facilitating adult learning: A comprehensive analysis of principles and effective practices. San Francisco, CA: Jossey-Bass, 1986

13. Siehl C, Martin J. The role of symbolic management: How can mangers effectively transmit organization/ culture? Elmsford, NY: Pergamon, 1984:227-39.

14. Pfeffer K. Management as symbolic action: The creation and maintenance of organizational paradigms. Greenwich, CT: JAI Press, 2002.

15. Anderson MS, Louis KS. The graduate student experience and subscription to the norms of science. Research in Higher Education 1994;35:273-99.

16. Anderson MS. Misconduct and departmental context: Evidence from the Acadia Institute's Graduate Education Project. J Infor Ethics 1996;5:15-33.

17. Bebeau MJ, Thoma SJ. The impact of a dental ethics curriculum on moral reasoning. J Dent Educ 1994;58:684-92.

18. Lambros A. Problem-based learning in middle school and high school classrooms. Thousand Oaks, CA: Corwin Press, 2004

19. Daggett W, Houston S. Facilitating Learning. New York, NY: Leadership Press, 1998

20. Vallance RJ. Formation in Research Ethics: Developing a teaching approach for social sciences. AARE Conference 28th Nov-2nd Dec The University of Melbourne. 2004.

21. Rest J, Narvaez D, Bebeau M, et al. A neo-Kohlbergian approach: the DIT and schema theory. Educ Psychol Rev 1999:11:291-324.

22. Rest JR, Narvaez D, Thoma SJ, et al. DIT2: Devising and testing a revised instrument of moral judgment. J Educ Psychol 1999;91:644-59.

23. Bebeau MJ, Pimple KD, Muskavitch KMT, et al. Moral Reasoning in Scientific Research: cases for Teaching and Assessment. Bloomington, Indiana: Indiana University Poynter Center, 1995.

24. Iserson KV. Principles of biomedical ethics. Emerg Med Clin North Am 1999;17:283-306, ix

25. Kalichman MW. Responding to challenges in educating for the responsible conduct of research. Acad Med 2007:82:870-5.

26. Anderson MS, Horn AS, Risbey KR, et al. What do mentoring and training in the responsible conduct of research have to do with scientists' misbehavior? Findings from a National Survey of $\mathrm{NlH}$-funded scientists. Acad Med 2007:82:853-60.

27. Vallero DA. Beyond responsible conduct in research: new pedagogies to address macroethics of nanobiotechnologies. J Long Term Eff Med Implants 2007;17:1-12

28. Jones NL. A code of ethics for the life sciences. Sci Eng Ethics 2007;13:25-43.

29. McCabe DL, Trevino LK. Academic dishonesty: Honor codes and other contextual influences. J Higher Educ 1993;64:522-38. 